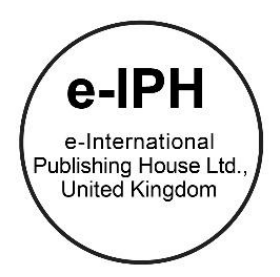

\title{
Place-based Learning and Change of Sense of Place: Educational program in a historic town
}

\author{
Huichin Huang ${ }^{1}$, Shenglin Elijah Chang ${ }^{2}$ \\ ${ }^{1}$ Ph.D. Candidate, Graduate Institute of Building and Planning, National Taiwan University \\ Lecturer,Chien Hsin University of Science and Technology \\ ${ }^{2}$ Professor, Graduate Institute of Building and Planning, National Taiwan University
}

heidiime@gmail.com

\begin{abstract}
Daxi is a famous historical town of north Taiwan, because of the preservation of the historic buildings of streets. It began to build the home identity of the locals from the 1990s. By the community participation shown the ancient culture of the town successfully, it became an attractive place for the tourism in Taiwan during the recent ten years. While the industry and lifestyle in the town are changing, it has a bearing on the power of the community groups. The life in the town is not convenient and low quality. Young people were left to work outside the community, and the social relation is to harden into stone. By the time goes on, the sense of place is changing to reconstruct the "Local." While the industry changed, the culture is much different from the traditional, and the young people have a different dream of their home community. We found some alienated feeling in young people of the town from the workshop discussion of the "Dasi-field school". However, in recent three years, the eco-museum project by participating with the local people, and it stimulated some learning programs in the community. In these two years, some young people would like to stay in the community and have some creative businesses. The occurrence of educational activities facilitates the translation of local knowledge. Through this study, we tried to understand if local people's sense of place was changed, as well as young people's identity of community life. In this action research, firstly, we had data analysis about the community learning-landscape of the community. Finally, we want to discuss how learning programs make sense of the neighborhood change and flow. Based on experiential research, we came up with a learning landscape model, in an attempt to construct the interactive relation between learning and community identity. Furthermore, we presented a new partner relation between community development and the design of educational courses.
\end{abstract}

Keywords: local knowledge; sense of place; environmental education

eISSN: 2398-4287@ 2017. The Authors. Published for AMER ABRA by e-International Publishing House, Ltd., UK. This is an open access article under the CC BYNCND license (http://creativecommons.org/licenses/by-nc-nd/4.0/). Peer-review under responsibility of AMER (Association of Malaysian Environment-Behaviour Researchers), ABRA (Association of Behavioural Researchers on Asians) and cE-Bs (Centre for Environment-Behaviour Studies), Faculty of Architecture, Planning \& Surveying, Universiti Teknologi MARA, Malaysia.

https://doi.org/10.21834/e-bpj.v2i6.927

\subsection{Introduction}

The OECD (Organisation for Economic Co-operation and Development) discovered that the economy has transformed from being industry-oriented to being learning-and -innovation centered in knowledge fields. In modern society, knowledge and learning have also started to affect the development of local industries. In 2008, the Center for Educational Research and Innovation in OECD presented a project report, Innovating to Learn, Learning to Innovate. It raised educational issues in the future economy, indicating "How can learning within and outside schools be reconfigured in environments that foster the deeper knowledge and skills so crucial in our new century?"It also mentioned that the new values in the future society are not limited to its economical development but more about improving people's lives. "To success in this is not only important for a successful economy, but also for effective cultural and social participation and for citizens to live fulfilling lives." (Center for Educational Research and Innovation, 2008:11)

eISSN: 2398-42870 2017. The Authors. Published for AMER ABRA by e-International Publishing House, Ltd., UK. This is an open access article under the CC BYNCND license (http://creativecommons.org/licenses/by-nc-nd/4.0). Peer-review under responsibility of AMER (Association of Malaysian Environment-Behaviour Researchers), ABRA (Association of Behavioural Researchers on Asians) and cE-Bs (Centre for Environment-Behaviour Studies), Faculty of Architecture, Planning \& Surveying, Universiti Teknologi MARA, Malaysia.

https://doi.org/10.21834/e-bpj.v2i6.927 
Going along with the trend of localization around the globe as well as globalization and sustainability thinking, in rural areas, there are different possibilities from previous industries. Through displaying a culture of a community, the correlation of lives and lands becomes closer. In this online era, young people can access to the world through using learning media and web resources. The spatial limitations have been broken down due to circulating information on the Internet. With slow value addition, tourists have also been attracted. However, not spatial management does not just come from lives. Recently, through actions in local cultural industries, with regards to spaces, the conservative thoughts have been broken through. This makes local residents identify with the culture of a community and participate activities in a community; therefore, a new pattern of urban-rural development has been produced.

Since the community management and creation of Daxi Culture Festival in 1996, starting from the historical space and culture of a small town, local residents have established an identity of their home. Additionally, due to the perseverance and maintenance in the era of Japanese rule, its unique humanity and landscapes are important tourist sites in North Taiwan. After 2000, the development of tourism also brings industrial opportunities and developmental imagination to the place.

However, the new development of industries also changes the life pattern of this place. In the past, social networking organizations were life-oriented but they are now industrial development-oriented. The establishment of local identity has gradually produced a sense of distance in the historical description that is unrelated to modern lives. In the past ten years, the outflow of young people, the endangered traditional wood art skills, the filling of stands in the historical boroughs have decreased the living quality in the locale. The separation of industries and living culture becomes a critical issue that has to be faced by the community.

"A place is a meaningful space, which carries the lives and emotions of communities. Through the practice of daily lives by communities, the projection of place emotional attachment transforms to local identity. The intensity of interactions between people and surroundings would also affect the depth of local identity.(Tu, 2014)"

During the industrialization and commercialization process of Daxi, we found that teenagers have been separated from there. Tourism makes the gap of lives and industries bigger. With credentialism in family values, the young generation also lacks caring and participation in a community. During the workshop in 2011, kids indicated, "I feel there are no young people in the old borough! "To teenagers, the places that are the most memorable to them are fried chicken stores, net cafes, and chain restaurants which also make us want to learn from our experiences to enrich these young people's sense of place.

This study started from the reflection of the learning experience and local identity. Through personal interactions during the course, we found expression of local lives. Additionally, the social relationship between young people and students as well as the place were connected by educational activities. Through the activities, local knowledge has been reconstructed and the social power of the community has been awakening.

\subsection{The sense of place}

The place is a noun that has multiple meanings: it ranges from physical space to emotional memory in one's mind. In The Aesthetics of Architecture, Roger Scruton mentioned spatial essentialism: spaces, spatial relations, and spatial connections are true objects of architectural experiences. Space is an experienced object of substance. However, a relation and connection in a space also affect the object's subjective feelings. Since 1970's, humanistic geologists started developing place researchers. A place expresses concepts that face the world, which emphasizes its objectivity and experience, instead of cold and emotionless logics of spatial science (Gresswell, 2006). From a research perspective of humanistic geology, space is not only a three-dimensional physical space, but it also satisfies human beings' needs in lives as well as the civil development. We also include the human factor. Therefore, space is not only a container, but it is also a place that carries lives and stores memories.

To define a place more clearly, Relph (1976) thinks that a place includes three ingredients: physical surroundings, human activities, and its psychological meanings, according to his categorization. Among the three ingredients that a place includes, it is harder to handle and confirm its psychological meanings than the other two ingredients; therefore, it is especially important (Tuan, 1998). When people project meanings to a specific space by attaching to it in a certain way, space then becomes a place (Gresswell, 2006). That is to say, a place is the psychological existence of space.

From the experienced phenomenological analysis, including people's daily life experiences, Relph(1976) thinks that a place is a geological phenomenon of daily experiences in the life-world. Being rooted in a place, namely, keeping a base point that prospects the world, captures one's position firmly in the order among various things, and has important spiritual and psychological attachment to a special place. He thinks space has its complexity, which is based on the real places that real people encounter during their daily lives. On the other hand, people's sense of place would change due to accumulated experiences.

"The sense of place is the psychological feeling that a place brings", therefore, the sense of place is usually related to the production of emotions and feelings that people and places connect with. When we can differentiate different places, or sense that different places have different characteristics, the sense of place has been formed ( $\mathrm{He}, 2014$ ). The occurrence and accumulation of the sense of place are due to the occurrence of experiences. The course on community education uses the community space as an object. Through different perspectives, to observe and enhance the interactions between people and surroundings, and to design learning contexts, the communication and interactions among various generations are made to enhance the sense of place and local identity. 


\subsection{Learning landscapes as online learning classrooms}

A landscape is different from an objective space. It is a visual representation of people and nature: a landscape is not only a landform that had been paid attention to, or a materialized object about experiences, but a form of cultural representation (Lin Y., 2011; Cosgrove\& Dainels, 1988). To know the culture in a community, one can start from knowing its landscape. People have a habit of visual learning: from the visual observation, the difference and identity can be found; that is an excellent way to elaborate the sense of place. This study started focusing on landscapes: from observing and interpreting the elements of landscapes, we can see the sense of place and local identity of the learners.

Based on the theory of learning space, "The Learning Landscape is the total context of students' learning experiences and the diverse landscape of learning settings available today-from specialized to multi purpose, from formal to informal, and from physical to virtual." (Dugdale 2009). Learning landscapes are not only physical spaces where learning occurs; they are also organized spaces under the learning communities.

Through different teaching strategies, different spaces and knowledge networks are present; the multiple characteristics of learning landscapes are also shown:

The goal of the Learning Landscape approach is to acknowledge this richness and maximize encounters with people, places, and ideas, just as a vibrant urban environment does.(Dugdale 2009)

The concepts of learning landscapes are equipped in the theory of innovative education. Due to the cultural diversity of learning landscapes, it will proactively change the teaching methods in the future. Here we highlight the shift from the singular homogeneous didactic teaching spaces, towards the much more heterogeneous learning landscape across the multiple scales of spaces we have identified, and towards learning environments which we believe will be increasingly service oriented, more performative, and led by the demands of the users. (Jonas N. \& Andrew L.,2015). Jonas N \& Andrew L also presented the Networked Learning Landscape model (Fig. 1).. They tried to connect different learning patterns with the management of a learning environment and presented the proactive effect that learning landscapes as a learning environment can facilitate innovative teaching.

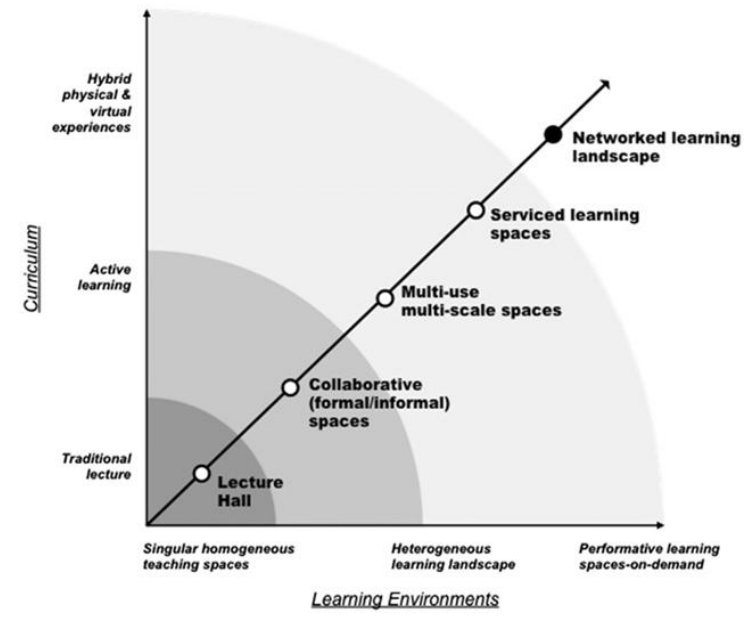

Fig.1 The networked learning landscape model (Jonas N. \& Andrew L.,2015)

\subsection{Place-based learning}

The Oxford English Dictionary defines knowledge as the following: it has a characteristic, that is, it is a gained and perceived fact or truth through personal thinking ( Lai, T. et al., 2007).

Professor Huang Wu-Hsiung presented that "Knowledge without experiences dissimilates people." He said "if people only rely on instilling and learning knowledge by school education, instead of reflecting one self's observation and experience, then abstractness dominated concretization, commonness also flattened specialness, essence covered existence, and people's appearance became blurry. People themselves then dissimilate as tools of the conceptual world. (Huang, W., 1998)"

Knowledge on the textbooks and classroom speeches are mostly abstract knowledge. Huang Wu-Hsiung reminded that during learning, it is dangerous to learn the abstract and common concepts via knowledge. In addition, how to motivate the learning and delivery of local knowledge to satisfy the knowledge enrichment of individuals in authentic social contexts should be emphasized and designed in the future educational strategies.

In environmental education, an academic term, place-based education, was presented. It emphasizes the real-world learning experiences. Place-based education is the process of using the local community and environment as a starting point to teach concepts in language arts, mathematics, social studies, science and other subjects across the curriculum. (Sobel, 2004). Also according to one of the philosophers in the seventeenth century, Comenius, "Knowledge of the nearest things should be acquired first, then that of those farther and farther off.. (Woodhouse, 2001; Sobel, 2004)", place-based education starts from there, such as investigating the food system and exploring the wetlands in outdoors. 
Some experts have ideals from cultural-ecological principles. They think the reciprocal relationship between people and their environment takes the form of relational architectures and relational pedagogies. Space is given shape and identity by the relationships created within it. (Dillon, P.,2008; Ceppi and Zini,1998) Place-based learning lets learners gain knowledge from contexts in daily lives: daily experiences of landscapes, such as interpersonal interactions, and traditional culture. It is an opening of knowledge as well as the liberation of citizens. Students know more about their own communities and establish more aspects of interpersonal relations. It also facilitates the participation of communities and self-actualization of young people and students.

\subsection{Action Research: Place-based learning program in Daxi}

With the role of community participation in the Daxi community, we discussed in the Daxi Urban Renewal Project in 2010. The old borough in Daxi has been cultivated for many years; therefore, the residents' mobility and local awareness is high. However, at that point, we observed these two phenomena: first, there are insignificant young people among the participants; second, the participants are mostly the residents in the old borough. Therefore, we have two action issues: under the current educational mechanism, could there be more connection between the youths and community? How can more people be included in the management and creation of an industrialized community? By using educational activities, we try to awake the local awareness of the youths. Since 2011, we have started a summer workshop at a senior high school: Digging in Daxi. So far, there have been seven years.

\subsection{JHIH SHAN High school - Digging in Daxi}

Class goal: To make local young people get out from their homes and schools as well as enter the community to cultivate humanistic care. To broaden the students' horizons, we held a workshop that offered project-based classes during summer. In the games, we facilitated learning, collaboration, and growth of interpersonal relations.

Class design: Teaching activities that are locally and culturally cognitive were implemented, such as Impression on Daxi, Lives in Daxi, History of Daxi, and Digging Daxi. And the last one, Creation about Daxi, the students displayed Daxi with the use of dramas as media. Among the last creation, local youths' identity was displayed through body crafts. It also refreshed their local identity and displayed alternative thoughts, which also raised a different discussion on the sense of place and local awareness.

Learning Context: The course was three-day long. On the first day, the students were led to discover different places in the community. With the use of field games, the students were facilitated to observe landscapes. On the second day, the students self-chose a place to interview and interact with the community residents. They also worked on projects where they created films and expressed their feelings through dramas. On the third day, they presented their films and works in the classroom at the school.

Learning Situation

\begin{tabular}{lll}
\hline Lives in Daxi & Subject \\
the Yi-He village & Explanation
\end{tabular}




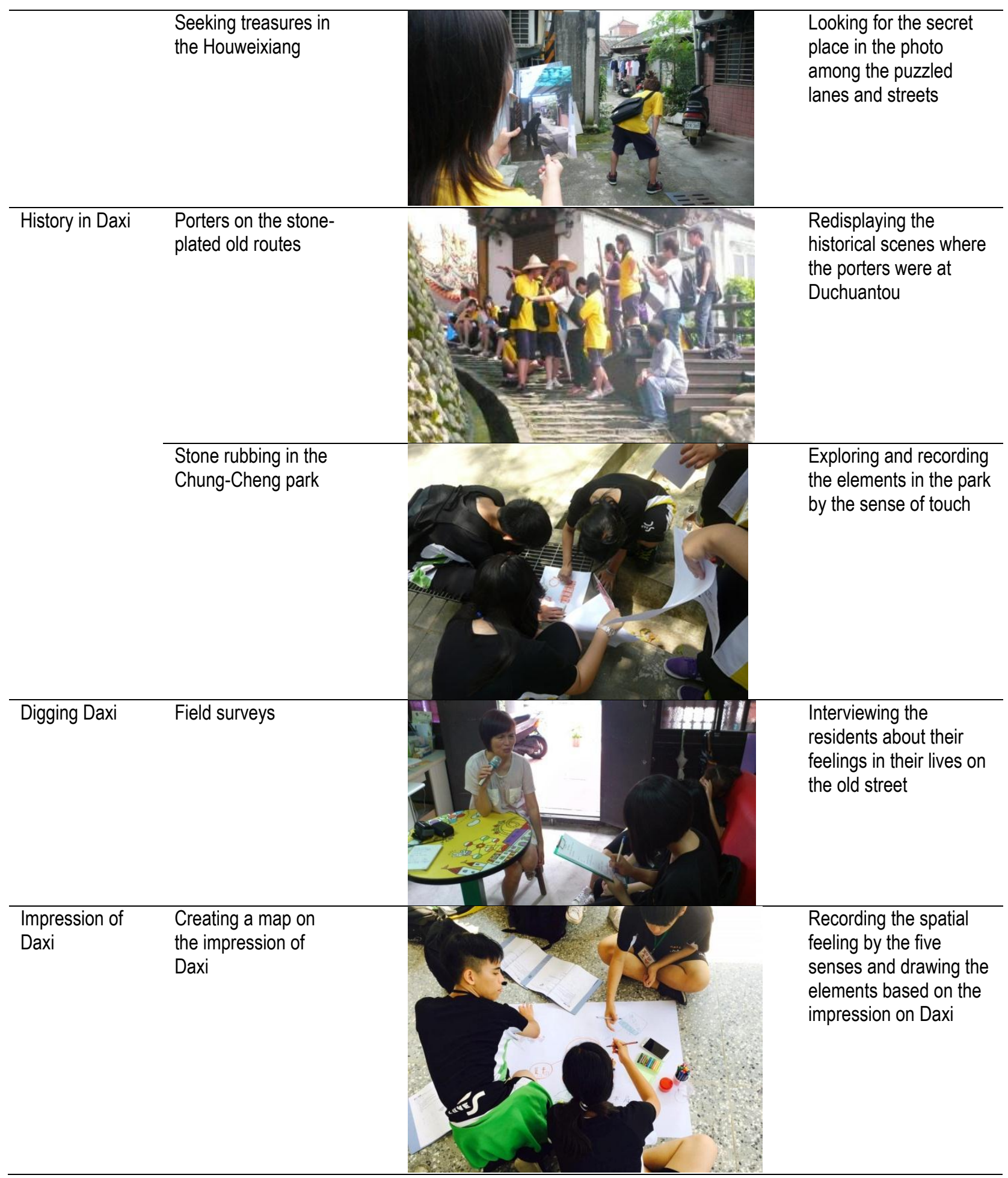




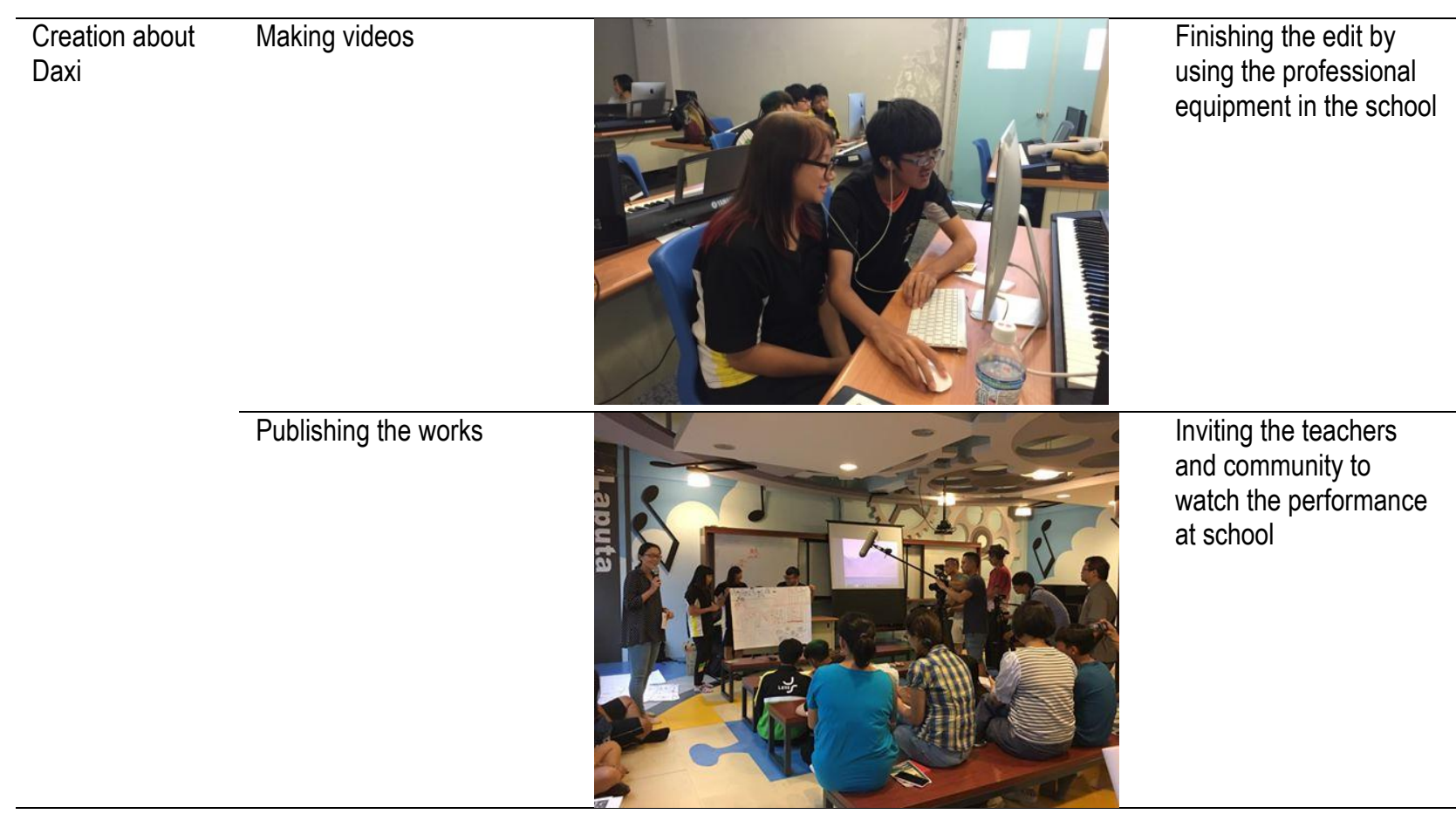

(Image source: photo by the researchers)

\subsection{Daxi Field School}

The data of the local culture ins Daxi is mostly about the canals, which lack written records on other groups and spatial spaces. When we think about how to bring different groups' viewpoints, we try to start from the liberation of local knowledge. Hence, since 2016, we have collaborated with the Daxi Field School. The participants have not limited anymore, including junior high school students, the students in Jhih-Shan High School, college students, non-students, and retired people.

Class goal: your ordinariness is my visional experience. During the classes in Daxi Field School, starting from our simple lives, we share our experiences with each other. We try to open new angles and get to know the community from a different perspective.

Class design: The dining table stories were used as the subject. The food culture among the households was recorded and surveyed with the residents in the community. A variety of life stories and scenarios were dug to be the projects of the small groups. The representative life stories were found to shoot and make videos revolving around dining table stories.

Learning Situation:

Eating seasonal
food




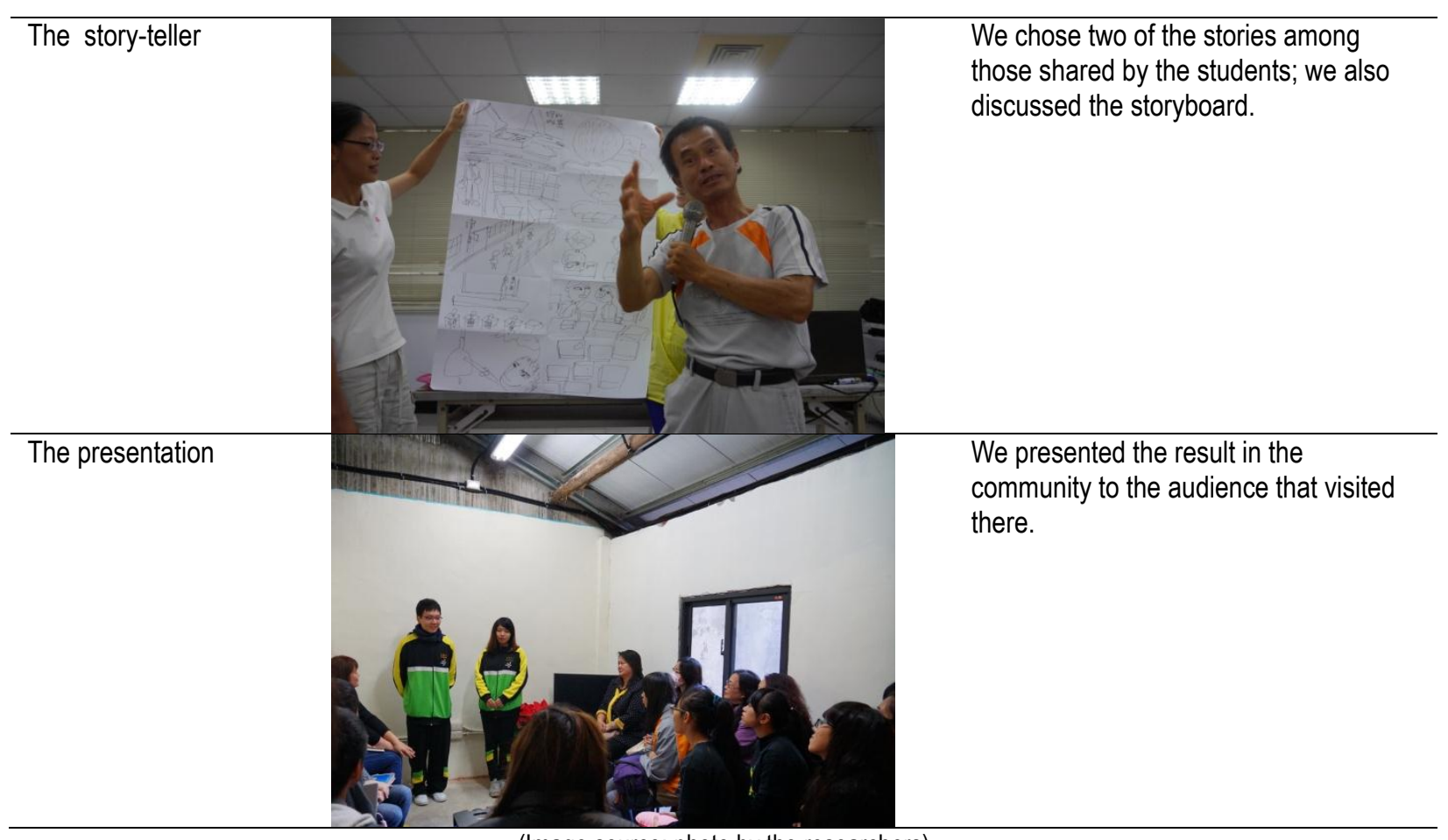

(Image source: photo by the researchers)

\subsection{From the senior high school courses to the community}

In this study, through the design of field observation courses, the learners were led to observe the landscape. The design of the advanced field survey made the learners have interpersonal interactions and then reconstruct the landscape. The process of constructing and reconstructing also enriches the diversity of the landscape in Daxi. In this action research, the transformation and diversity in an educational context can be seen. From being homogeneous to non-homogeneous of the learning communities, the concepts presented in multi-scale integrated networked learning landscape (Jonas N. \& Andrew L.,2015) were used as a reference. In this study, as an innovative education model, the managing process of learning landscape is summarized, which has these two features(fig. 2):

(a) Reconstructing the relation between the community and education: ranging from practical teaching design of the teachers and inquiry-based game learning, to field surveys on the community culture as well as the learning network constructed between the school and community, the profession in school is assimilated into daily lives; we also created an interactive teaching context revolving around local knowledge with the community.

(b) Teaching design that is learner-oriented: by constructing this kind of network, the students stepped into an authentic community. Problem-oriented classes also stimulated the students to learn by themselves. The students demonstrated their sense of place to the community in multiple forms.

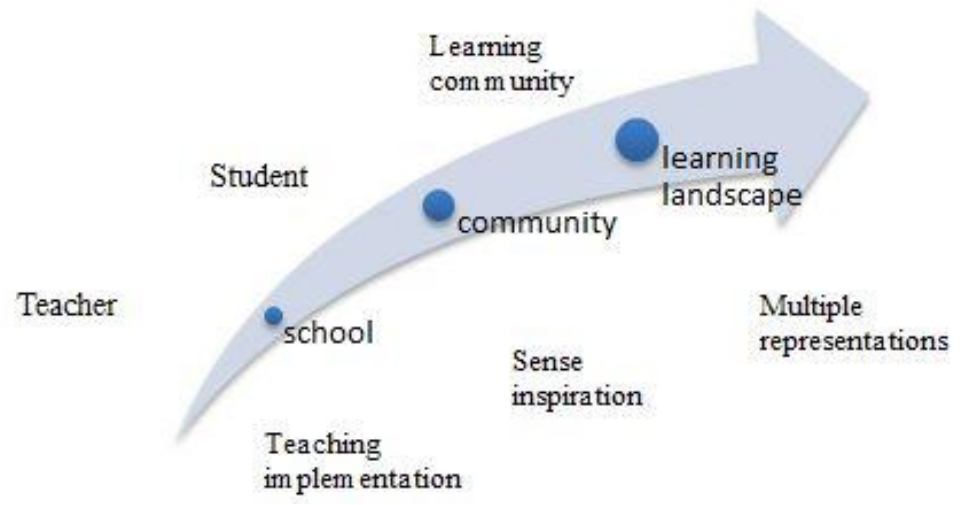

Fig.2 Construct a learning landscape 


\subsection{Effectiveness analysis on the place-based classes}

Through the classes, we cultivated the awareness of place in Daxi. Aside from the expansion of community participation, on the other hand, we also see students' learning improvement and cultivation of creativity. In this section, we used the concepts on reconstructing the place to analyze the effectiveness of the course.

\subsection{Reconstruct the place}

The class is designed mainly based on the creation of experiences and local learning. The body experience happened in the authentic world may not be able to be expressed in languages. After the immediacy of bodies, texts, images, or other forms can be used to construct theories (Duwey, 2006).

The students' local awareness can be analyzed: we can see the correlation between their local awareness and community care through their impression maps and the creation of videos. It is shown in the following:

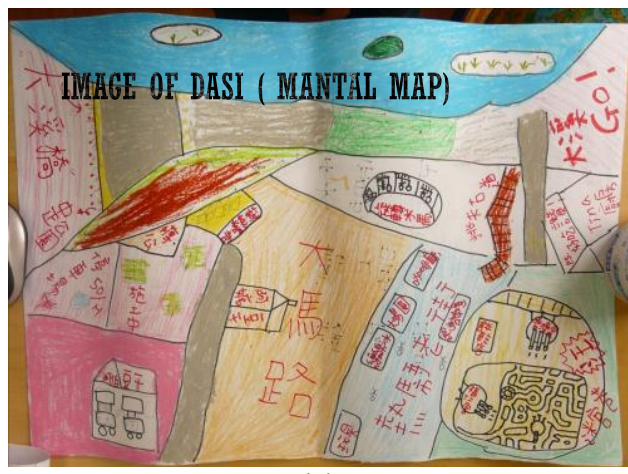

(a)

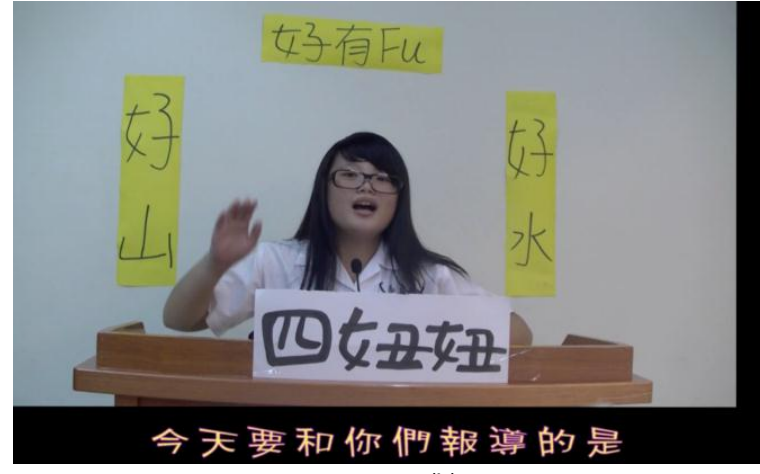

(b)

Fig.3 (a)Through the impression map in Daxi, we can see the students' observation on the traffic in the community. (b)In the video of Daxi news, we interviewed the residents on their feelings about the lives in Daxi. (Image source: photo by the researchers)

After the course ended, from the students' feedback, we could see their experiences expanding, as well as their local identity and community participation:

"I'm really amazed that there is such a place like Migongxiang! (Describe by student Y.)"

"I hope we can find people outside of the school to know more about Daxi. (Describe by student L.)"

Most of the local knowledge on the community field is acquired by body experiences, or presented by its objective knowledge, where the translation of personal knowledge is necessary. Through educational activities in a community, real sense and feeling are a way to pass down the local knowledge. On the one hand, it is used as a learning method for tacit knowledge; on the other hand, it becomes the medium of constructing local awareness through the creation of body experiences and reflecting the feeling and sense by activities, which could also be the media of constructing local awareness.

\subsection{The learning environment}

From an educational perspective, especially for the students who are motivated by technical and practical learning, spatial experiences can arouse their learning interests. Interacting authentically also makes the students more creative and stimulates their implementation on learning.

"I can know a lot about the old culture in Daxi. Hmmm, maybe it's not the culture, but industries, such as porters. Also, Migongxiang...l've been to Daxi before, but I never went there. So I though I would take a quick look and leave. However, when I was there, I realized Feng Feifei's home is there. That was pretty cool! And there are also a lot of places that are worth a visit. (Describe by Student C.)"

"I feel this class is quite different. In other classes, we were sitting obediently in the classroom and taking notes. But in this class, we have done a lot of outdoor activities and played games. (Describe by Student S.) "

On the one hand, the stimulation of learning motivation is the accumulation of current knowledge; on the other hand, it is the learning desire from a person's within. To solve the problems, how did this kind of awareness occur? Freire started discussing from Sartre's argument about intentionality. "Bringing the consciousness to the existent world and through self-reflection and the world, it opens the awareness. When that occurs, it becomes a kind of problem and challenge (Freire, 2004)."

"This time, I did have interaction with the land, and I'll start thinking about the relation between Daxi and I. (Describe by Student L.)" 
The awakened consciousness is closely related to the authentic world. Learning by bringing the consciousness in an educational environment to the authentic world, also from the design of educational contexts and the opening of dialogues to facilitate reflection, the valuable awareness of local experience was aroused.

\section{Conclusion: The innovation from the local community}

Through designing and discussing professionally, the planners translated the place. Activities based on spatial production are used to maintain the ordinary local culture. In today's society in Taiwan, it is more needed that we bring an innovative and local energy from the bottom up through arousing local awareness. Especially a public community that is like Daxi, it has been managed and created for twenty years. In a socially structuralized relation and social space, we broke through the traditional routes by the planners. We expect through educational activities, people can develop public awareness and there can be multiple presentations and dynamic energies.

Overall speaking, in the community educational activities, through the construction of the sense of place, there are two aspects:

(a). The local identity of body experiences: through the course design, people of various ages and communities were motivated, and the local social relation was disturbed.

(b). A communicating platform for local knowledge: through the course design and the display of an online platform along with a variety of local discussions, observation on local diversity among cultures and local awareness were presented.

We started thinking from the place-based learning in educational designs. Not only do they activate community spaces, but also bring young people to the knowledge platform into communities and facilitate their participation. To summarize, the display of learning landscapes in communities and persistent management has its proactive effect.

(1) Participating in platform innovation to bring sustainable management locally

From participation in communities and education, urban designs and plan can be assimilated to local contexts and local developmental issues. At the same time, the ability of publicly participating in democratic discussions of local people can be improved. From an educational aspect, by community participation, the spatial education is assimilated into the place and school, which also facilities multiple learning. From a participation aspect, by the use of spatial education, the awareness of residents and young people is improved. So that makes the future plans can deepen into the local people and think more rationally and insightfully.

(2) Diversified local and cultural identity

From the current situations in the old boroughs, the identity is constructed based on the spatial and historical footprints. It is mostly the identity on the figurative buildings, such as archways. The cultural value on consumption-orientation comes from the single value developed by the tourism by the local government. This kind of cultural identity is a danger. How do we make the deeper culture in Daxi emerge? How do we dig the deeper ordinary culture in Daxi through the participation through local groups and local education provided by educational institutes? It then becomes the primary concern to think about how to connect Daxi with the local life experiences while facilitating the sustainable development in the community.

(3) A new partnership with the intervention of education

The promotion of local management and creation can be attempted to combine with the course design in school. With the input of resources from both sides can shorten the distance between young people and Daxi and a closer emotional interaction will be had. It also makes the development in Daxi equip with the young people's energy and perspective. Furthermore, it means that future Daxiers are cultivated, which also passes down the culture.

Additionally, educational institutes have enough conditions and resources to be responsible for the tasks for local industry development. For example, the wood craft course cooperated with traditional wood crafters can be the featured course in school which is also helpful for attracting students. On the other hand, it also solves the problem of lack of talents in traditional industries. It can also continue and innovate on the management of industries. An internship place is provided in the community, and the human resources are provided by educational institutes. Based on this, educational institutes can be in a partnership with the development of local industries.

(4) Managing educational contexts and urban and rural development

A community is a large display where the buildings and life contexts are the content that it displays. The display of local knowledge offers a field for learning local culture. Long term, diversified, continuous, adaptive, and flexible courses and activities in the community are developed. The activation strategy in Daxi should be turned to the urban renewal strategy, which focuses on the innovation on software management and then the activation of hardware reaction; the value of renewal and activation of the space in the borough comes from the ideal activities in there and the extensive management strategy, such as managing learning landscapes. When we think about passing down the culture to local youths, it can even be combined with the current courses on tourism about cultural development and innovation. By doing so, we can maximize the effects of local resources more efficiently. 


\section{References}

Center for Educational Research and Innovation (2008). Innovating to Learn, Learning to Innovate. Paris: OECD Publishing. DOl:http://dx.doi.org/10.1787/9789264047983-en

Ceppi, G., and M. Zini. 1998. Children, space, relations: Metaproject for an environment for young children. Reggio Emilia, Italy: Commune di Reggio Emilia and Ministero della Pubblica Instruzion.

Cosgrove, D., \& Dainels, S. (Eds.). (1988). The Iconography and Landscape: Essays on the Symbolic Representation, Design and use of Past Environments. Cambridge: Cambridge University Press.

Cresswell, T. (2006). Place : a short introduction. (Hu, T\& Wang, C. , Trans.). Taipei : Socio Publishing.( Original work published 2004)

Dewey, J. (2006). Democracy and education. (Hsueh, H. ,Trans.). Taipei: Internet and book publishing. .( Original work published 1916)

Dillon, P. (2008). Creativity, Wisdom, and Trusteeship: Niches of Cultural Production. In Craft, A., Gardner, H. \& G. Claxton (Eds.). Creativity, wisdom, and trusteeship: exploring the role of education. CA : Corwin Press.

Dugdale, s(2009). Space Strategies for the New Learning Landscape,Educatuse Review, March/April. Retrieved Retrieved Aug. 10 from: https://er.educause.edu/ /media/files/article-downloads/erm0925.pdf

Freire, P. (2004). Pedagogy of the oppressed, 30th anniversary ed. ( Fang, Y. Trans.). Taipei : Chuliu. ( Original work published 1974)

He, Hsin-hua (2014). Visitor 's sense of place and space reproduction. Paris Vision, Vol.29. Taipei : Sino- French Cultural and Educational Foundation.

Huang, Wu-hsiung(1998).Human beings are ends. Retrieved Aug. 1, 2017, from http://www.hkshp.org/newsgroup/99-07ends.txt

Jonas N. \& Andrew L. (2015). Designing spaces for the networked learning landscape, Medical Teacher, 37:4, 337-343, DOI: 10.3109/0142159X.2014.1001349

Lai Ting-ming et al., (2007). Research on tacit knowledge. Taipei: Mandarin Library\& Information Service co..

Lin, Yu-chun (2011). Rural, Multi - functional and Taiwan 's Rural Cultural Planning and Remodeling , In Wu ,Genming, and Zeng, Guangzheng (Eds.).A Proceedings of the Symposium on Social Development in South Taiwan. Pingtung: National Pingtung University.

Neary, M., Harrison, A., Crellin, G., Parekh, N., Saunders, G., Duggan, F., et al. (2010). Learning landscapes in higher education: Clearing pathways, making spaces, involving academics in the leadership, governance and management of academic spaces in higher education. Lincoln: Centre for Educational Research and Development. Retrieved Aug. 23, 2017, from http://eprints.lincoln.ac.uk/18960/1/FinalReport.pdf

Relph, E. C. (1976). Place and placelessness. London: Pion.

Sobel, David. Place-based education: Connecting classroom and community. Nature and Listening, 4 (2004): 1-7. Retrieved Aug. 31,2017, from http://www.kohalacenter.org/teachertraining/pdf/pbexcerpt.pdf

Tu, Pei-Ching (2014). Considering the Construct of Local Identity Based on the Migratory Journey of the Kucapungane, Journal of Building and Planning, 22(2) DOI: 10.6154/JBP.2017.22.002

Tuan, Y. F. (1998). Space and Place: The Perspective of Experience.( Pan,K.,Trans),Taipei: National Translation and Compilation Center ( Original work published 1977)

Wei, Kuan-chu (2011). Reflections on the Phenomenological Geography of Modern Space by the Composition of Local. Joint Catalog of Digital Collection and Digital Learning. Retrieved Aug. 31,2017, from http://catalog.digitalarchives.tw/item/00/5f/12/7c.html.

Woodhouse, Janice. (2001). Over the River and Through the Hood: Reviewing Place as a Focus for Pedagogy.Thresholds in Education, 27, nos.3 and 4. 